\title{
Hepatic megalocytosis in wild and farmed chinook salmon Oncorhynchus tshawytscha in British Columbia, Canada
}

\author{
Craig Stephen ${ }^{1,2}$, Michael L. Kent ${ }^{1, *}$, Sheila C. Dawe ${ }^{1}$ \\ ${ }^{1}$ Department of Fisheries and Oceans, Biological Sciences Branch, Pacific Biological Station, Nanaimo, British Columbia, \\ Canada V9R 5K6 \\ ${ }^{2}$ Department of Veterinary Microbiology, Western College of Veterinary Medicine, Saskatoon, Saskatchewan, \\ Canada S7N 0W0
}

\begin{abstract}
Hepatic megalocytosis in fish has been used as a biondicator for exposure to xenobiotics. However, this lesion is also induced by natural toxins and has been observed in fish from apparently unpolluted waters. Hepatic megalocytosis was observed in $16.0 \%$ of chinook salmon Oncorhynchus tshawytscha that had returned to spawn at 3 freshwater hatcheries on Vancouver Island, British Columbia (B.C.), Canada, and was observed in $7.0 \%$ of ocean-caught chinook in this area. The lesion was not detected in 175 wild-caught sockeye salmon $O$. nerka. A greater proportion of wild chinook were affected when compared to farmed chinook of a similar age that were reared in seawater netpens (12.3 vs $1.5 \%$ ). This survey demonstrates that hepatic megalocytosis is prevalent in wild chinook salmon in B.C., but the cause of the lesion is unknown.
\end{abstract}

\section{INTRODUCTION}

The liver of fish is known to be a target organ for xenobiotic toxicants and carcinogens (Myers et al. 1987), and hepatic megalocytosis (HM) is often used as bioindication of exposure to such agents (Hinton et al. 1992). HM, also known as megalocytic hepatosis, may be, in one interpretation, the failure of cell division in mitosis, resulting in polyploid hepatocytes with an extremely enlarged cytoplasm and nucleus (Myers et al. 1987, Hinton et al. 1992). The lesion has been induced in fish experimentally exposed to several chemical agents (Eller 1971, Couch 1975, Hinton et al. 1978, Couch \& Courtney 1987), and has been observed in wild fish from polluted waters (Myers et al. 1987 , Peters et al. 1987, Hinton \& Laurén 1990). However, epizootics of severe HM have been observed in fish that were not associated with exposure to a recognized xenobiotic (Kent et al. 1988, Kent 1990, Groff et al. 1992), and this lesion is occasionally found in wild fish from apparently unpolluted waters (Malins et al. 1984).

\footnotetext{
- Addressee for correspondence
}

Recently, as part of a disease survey, we found HM in several wild chinook salmon collected in coastal waters of southern British Columbia (B.C.), Canada.

\section{METHODS}

This survey was conducted between April 1991 and November 1992. Farmed and ocean-caught salmon were collected throughout the year, whereas salmon that had returned to fresh water to spawn were sampled in the autumn of 1991 and 1992. A total of 1340 salmon were examined from 13 locations in coastal areas of Vancouver Island and off the southern mainland of B.C. Locations for fish collection were determined by accessibility, cooperation with aquaculturists and fishermen, and availability of salmon. After killing the fish by a blow to the head, visceral organs were collected and then preserved in Davidson's solution (Humason 1979). The samples were prepared for routine histopathologic examination and slides were stained with hematoxylin and eosin.

The spawning salmon ranged in weight from 3 to 
$8 \mathrm{~kg}$ and were estimated to be 3 to $4 \mathrm{yr}$ old. All other fish, except for the freshwater group, were oceanphase salmon, aged 1 to $4 \mathrm{yr}$, that ranged in weight from 0.5 to $5 \mathrm{~kg}$. Farmed salmon were taken from commercial seawater netpen sites. Spawning wild chinook were collected at 3 freshwater hatcheries on Vancouver Island, B.C., and spawning wild sockeye salmon Oncorhynchus nerka were collected while returning to one of these hatcheries. Ocean-caught salmon, probably representing several stocks, were captured in the lower Strait of Georgia off the east coast of Vancouver Island. Chinook were captured by commercial trolling and sockeye salmon were captured by commercial gill netting. The freshwater group consisted of one hundred $2 \mathrm{yr}$ old male chinook that had been maintained in fresh water throughout their life. This group was held at a private hatchery and had been treated with testosterone during egg development to create an all-male (monosex) population.

For an individual fish to be considered to have HM, several hepatocytes demonstrating nuclear pleomorphism and enlargement of both nuclear and cellular diameters had to be found upon histologic examination. The criteria for inclusion in this study also required that at least some of the affected hepatocytes and their nuclei were 5 times larger than normal (Figs. 1 to 3 ). Cases demonstrating mild hepatocyte nuclear pleomorphism without significant increases in cell diameter were not included in the study.

\section{RESULTS}

Hepatic megalocytosis was most frequently observed in mature wild chinook that had returned to fresh water to spawn (Table 1). The lesion was seen in both the 1991 and 1992 runs of spawning chinook. Hepatic megalocytosis was seen in a higher proportion of the wild chinook as compared to the farmed fish (12.2 vs $1.5 \%$ ). The condition was not found in any of the sockeye salmon nor in the freshwater-reared chinook.

Table 1. Oncorhynchus tshawytscha and O. nerka. Prevalence of hepatic megalocytosis in chinook and sockeye salmon in British Columbia in 1991 and 1992

\begin{tabular}{|llcc|}
\hline & \multicolumn{1}{c}{ Group } & $\mathrm{n}$ & Prevalence (\%) \\
\hline Wild salmon & Spawning chinook & 353 & 16.0 \\
& Ocean-caught chinook & 257 & 7.0 \\
& Spawning sockeye & 75 & 0 \\
& Ocean-caught sockeye & 100 & 0 \\
& & & 1.7 \\
Farmed salmon & Spawning chinook & 65 & 1.5 \\
& Production chinook & 390 & 0 \\
\hline
\end{tabular}

The severity of liver changes varied considerably among fish. Fish exhibiting subtle HM had only a small number of isolated affected hepatocytes distributed diffusely throughout an otherwise normal liver. In severe cases essentially the entire liver parenchyma was affected (Figs. 1 \& 2). In such cases, panhepatic megalocytosis resulted in disruption of the normal architecture of the liver.

The common characteristic of all affected livers was the presence of hepatocytes with marked enlargement of nuclear and cytoplasmic diameters (Fig. 2), with some hepatocytes reaching $60 \mu \mathrm{m}$ and containing nuclei 30 to $35 \mu \mathrm{m}$ in diameter. Affected cells exhibited an atypical distribution of chromatin within vesicular nuclei, and the nuclei were often hyperpigmented. Pseudoinclusions, caused by herniation of the cytoplasm through the nuclear membrane, were evident in many of the hypertrophied hepatocyte nuclei (Fig. 2), and some hepatocytes were multinucleated. Hepatocellular necrosis and inflammation were minimal in most cases. There were no significant gross pathologic changes evident in affected livers. Examination of other organs, including the kidney, spleen, heart and portions of the gastrointestinal tract, failed to demonstrate gross or histologic signs that would be consistent with intoxication

\section{DISCUSSION}

The cause of HM in these salmon is unknown. Hepatic megalocytosis is observed in livers of vertebrates, including fish, following experimental exposure to known hepatotoxicants (Hinton et al. 1992), and HM has been linked to exposure to anthropogenic contaminants, particularly carcinogens, in coastal marine environments (Myers et al. 1987, Hinton \& Laurén 1990, Hinton et al. 1992). In addition, natural hepatotoxins such as aflatoxin (Wales 1967), pyrrolizidine alkaloids (Hendricks et al. 1981, Maddocks 1986) and microcystin LR (Kent et al. 1992) can cause HM.

We do not know the history of exposure to xenobiotic contaminants for the salmon in the present study. The cytomorphological characteristics of the hepatocytes in the affected salmon were not unlike those described for feral English sole Pleuronectes vetulus naturally exposed to multiple hepatocarcinogens (Myers et al. 1987). However, to our knowledge, the salmon in our study were from pristine waters.

The histologic changes in the chinook were also similar to those seen in netpen liver disease (NLD) of salmon, which is 


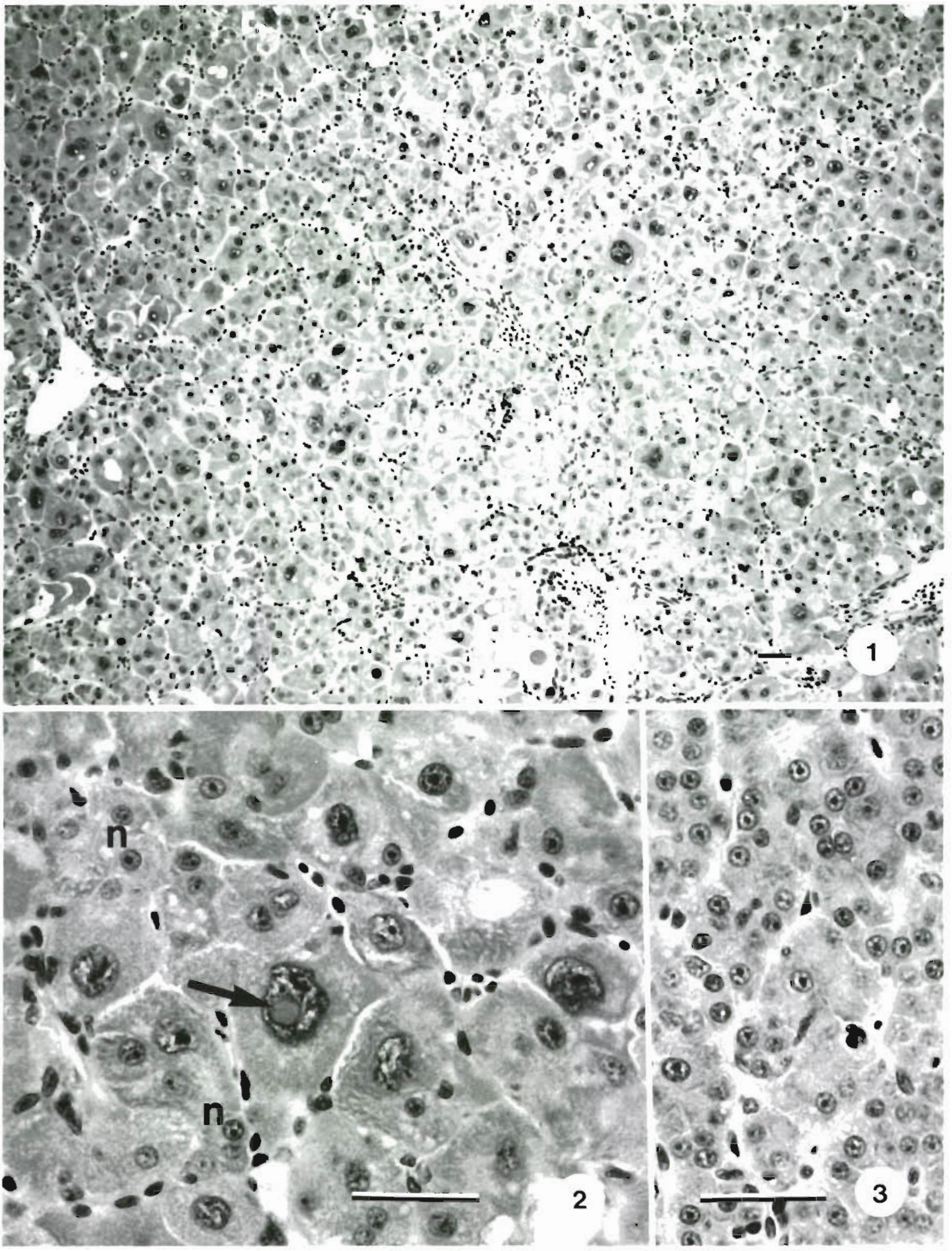

Figs. 1 to 3. Oncorhynchus tshawytscha. Fig. 1 Liver of wild-caught chinook salmon with hepatic megalocytosis. The normal tubular architecture of the parenchyma is absent, and the nucleus and cytoplasm of the hepatocytes are pleomorphic and vary greatly in size. Scale bar $=50 \mu \mathrm{m}$. Fig. 2. Liver of wild-caught chinook with hepatic megalocytosis. Note extremely enlarged, hyperchromatic nuclei with pseudoinclusion (arrow) and concomitant hepatocellular hypertrophy. n: normal size nucleus. Scale bar $=50 \mu \mathrm{m}$. Fig. 3. Liver of normal wild-caught chinook. Hepatic tubules are evident, and hepatocytes are similar in size and have relatively monomorphic nuclei. Scale bar $=50 \mu \mathrm{m}$ 
suspected to be caused by a natural toxin (Kent 1990). Netpen liver disease affects seawater pen-reared Atlantic salmon Salmo salar, rainbow trout Oncorhynchus mykiss, and chinook at several locations in B.C. and Washington State, USA (Kent 1990). As with NLD, HM only occurred in fish that had resided in sea water (Table 1), and was not associated with a recognized exposure to xenobiotics. In addition to HM, hepatocellular changes consistent with NLD include the formation of nuclear pseudoinclusions, multinucleate cells and necrosis. Affected livers also exhibit chronic inflammation. All of these changes occurred in the affected salmon in this study, except for prominent inflammation and necrosis. The latter 2 changes are more evident in early NLD, whereas HM can persist for many months after the affected fish are transferred to clean water and the acute changes have resolved (Kent 1990). Thus, the chinook in this study may have been suffering from a chronic form of NLD.

Observational and experimental evidence suggests that an algal toxin in the marine environment is the cause of NLD (Kent 1990). A chemical very similar to microcystin LR was detected in livers of fish with NLD (Andersen et al. 1993). Furthermore, lesions similar to those of NLD have been induced by injecting Atlantic salmon with purified microcystin LR (Kent et al. 1992). To our knowledge, HM has not been associated with microcystin exposure in higher vertebrates (Carmichael 1988) and other fish species, such as rainbow trout Oncorhynchus mykiss (Phillips et al. 1985) and carp Cyprinus carpio (Råbergh et al. 1992). However, these studies involved acute exposure experiments, whereas most of the Atlantic salmon exposed to high levels of the toxin survived and HM became evident only 2 wk after exposure (Kent et al. 1992). As with NLD of pen-reared fish, the wild salmon may be exposed to toxins (e.g algal toxins) by feeding on fish or invertebrates that have accumulated toxins through the food chain.

Hepatic megalocytosis may be observed in older mice (Frith \& Ward 1980), but the lesions observed in our study were considerably more severe. It is possible that the lesion is age-related in this study as spawning salmon had a higher proportion of HM than younger fish in both the wild and farmed salmon. However, due to the use of convenience sampling methods, these differences in proportion cannot be interpreted as differences in the true prevalence of HM in the populations. The influence of fish sex is not thought to be significant in the pathogenesis of HM in these salmon as the lesion was found in males, females and monosexed females, and the unaffected monosexed male fish were not subject to the important variable, seawater exposure.

The high prevalence of HM observed in the wild chinook suggests that the causative agent of this lesion in these fish is ubiquitous and available to wild and farmed salmon throughout the coastal waters of southern B.C. In addition, with a number of known causes of HM, it is possible that HM in the fish in this survey was caused by more than 1 agent. Although NLD has been diagnosed at several netpen sites in B.C. and Washington State (Kent 1990), the present study is the first report of prominent HM in wild and pen-reared chinook in B.C. The absence of the condition in sockeye salmon was unexplained. Perhaps sockeye are exposed to lower concentrations of, or are more resistant to, the putative toxin.

The observation of HM in wild fish from apparently uncontaminated water and the ability of natural toxins to produce the lesion demonstrates that caution must be exercised when one correlates HM with exposure to anthropogenic contamination. The possible association of HM with exposure to natural toxins and environmental pollutants further emphasizes that the pathogenesis and causes of this lesion in free and captive fish need to be more thoroughly investigated.

Acknowledgements. We thank Drs T P. T. Evelyn and J. W. Fournie for their review of the manuscript. This project was funded in part by the British Columbia Ministry of Agriculture and Fisheries and the Western College of Veterinary Medicine Wildlife Health Fund.

\section{LITERATURE CITED}

Andersen, R. J., Luu, H. A., Chen, D. Z. X., Holmes, C. F. B., Kent, M. L., Le Blanc, M., Taylor, F. J. R., Williams, D. E. (1993). Chemical and biological evidence links microcystins to salmon netpen liver disease. Toxicon (in press)

Carmichael, W. W. (1988). Toxins of freshwater algae. In: Tu, A. T (ed.) Handbook of natural toxins, Vol. III, Marine toxins and venoms. Marcel Dekker, Inc., New York, p. $121-147$

Couch, J. (1975). Histopathological effects of pesticides and related chemicals on the livers of fishes. In: Ribelin, W. E., Migaki, G. (eds.) The pathology of fishes. Univ. of Wisconsin Press, Madison, p. 559-584

Couch, J., Courtney, L. A. (1987). N-Nitrosodiethylamine-induced hepatocarcinogenesis in the estuarine sheepshead minnow (Cyprinodon variegatus): neoplasms and related lesions with comparisons to mammalian lesions. J. natl Cancer Inst. 79: 297-321

Eller, L. L. (1971). Histopathological lesions in cutthroat trout (Salmo clarki) exposed chronically to the insecticide endrin. Am. J. Pathol. 64: 321-336

Frith, C. H., Ward, J. M. (1980). A morphologic classification of proliferative and neoplastic hepatic lesions in mice. $J$. Environ. Pathol. Toxicol. 3: 329-251

Groff, J M., Hinton, D. E., McDowell, T S., Hedrick, R. P. (1992). Progression and resolution of megalocytic hepatopathy with exocrine pancreatic metaplasia in a population of cultured juvenile striped bass Morone saxatilis. Dis. aquat. Org. 13: 189-202 
Hendricks, J. D., Sinnhuber, R. O., Henderson, M. C, Buhler, D. R. (1981). Liver and kidney pathology in rainbow trout (Salmo gairdneri) exposed to dietary pyrrolizidine (Senecio) alkaloids. Exp. mol. Pathol. 35: 170-183

Hinton, D. E., Bauman, P. C., Gardner, G. R., Hawkins, W. E., Hendricks, J. D., Murchelano, R. A., Okihiro, M. S. (1992). Histopathologic biomarkers. In: Huggett, R. J., Kimerle, R. A., Mehrle, P. M. Jr, Bergman, H. L. (eds.) Biomarkers: bio-chemical, physiological, and histological markers of anthropogenic stress. Lewis Publ., Boca Raton, p. 155-209

Hinton, D. E., Klaunis, J. E., Lipsky, M. M. (1978). PCBinduced alterations in teleost liver: a model for environmental disease in fish. Mar. Fish. Rev. 40:47-50

Hinton, D. E., Laurén, D. J. (1990). Liver structural alterations accompanying chronic toxicity in fishes: potential biomarkers of exposure. In: McCarthy, J. F., Shugart, L. R. (eds.) Biomarkers of environmental contamination. Lewis Publ., Boca Raton, p. 17-57

Humason, G. L. (1979). Animal tissue techniques, 2nd edn. W. H. Freeman and Company, San Francisco

Kent, M. L. (1990). Netpen liver disease (NLD) of salmonid fishes reared in sea water: species susceptibility, recovery, and probable cause. Dis. aquat. Org. 8: 21-28

Kent, M. L., Andersen, R. J., Dawe, S. C., Williams, D. E., Le Blanc, M., Taylor, F. J. R. (1992). Microcystin LR: possibly the cause of netpen liver disease of seawater pen-reared salmon. Am. Fish Soc. Fish Health Sec. Newslett. 20(2): $9-12$

Kent, M. L., Myers, M. S., Hinton, D. E., Eaton, W. D., Elston, R. A. (1988). Suspected toxicopathic hepatic necrosis and megalocytosis in pen-reared Atlantic salmon (Salmo salar)

Responsible Subject Editor: D. E. Hinton, Davis, California, USA in Puget Sound, Washington, USA. Dis. aquat. Org. 4: $91-100$

Maddocks, A. R. (1986). Chemistry and toxicology of pyrrolizidine alkaloids. Academic Press, New York

Malins, D. C., McCain, B. B., Brown, D. W., Chan, S.-L., Myers, M. S., Landahl, J. T., Prohaska, P. G., Friedman, A. J., Rhodes, L. D., Burrows, D. G., Gronlund, W. D., Hodgins, H. O. (1984). Chemical pollutants in sediments and diseases of bottom-dwelling fish in Puget Sound, Washington. Environ. Sci. Technol. 18(9): 705-713

Myers, M. S., Rhodes, J. D., McCain, B. B. (1987). Pathologic anatomy and patterns of occurrence of hepatic neoplasms, putative preneoplastic lesions and other idiopathic hepatic conditions in English sole (Parophrys vetulus) from Puget Sound, Washington. J. natl Cancer Inst. 78: 333-363

Peters, N., Köhler, A., Kranz, H. (1987). Liver pathology in fishes from the Lower Elbe as a consequence of pollution. Dis. aquat. Org. 2: $87-97$

Phillips, M. J., Roberts, R. J., Stewart, J. A. (1985). The toxicity of the cyanobacterium Microcystis aeruginosa to rainbow trout, Salmo gairdneri Richardson. J. Fish Dis. 8: $339-344$

Råbergh, C. M. I., Bylund, G., Eriksson, J. E. (1992). Histopathological effects of microcystin-LR, a cyclic peptide toxin from the cyanobacterium (blue-green alga) Microcystis aeruginosa, on common carp (Cyprinus carpio L.). Aquat. Toxicol. 20: 131-146

Wales, J. H. (1967). Degeneration and regeneration of liver parenchyma accompanying hepatogenesis. In: Halver, J. E., Mitchell, I. A. (eds.) Trout hepatoma research conference papers Res. Rep. 70, Bur. Sport Fish. Wildl., p. 56-59

Manuscript first received: October 15, 1992

Revised version accepted: February 22, 1993 